\title{
HETEROGENEOUS AMORPHIZATION OF Cd IMPLANTED GaAs AT ROOM TEMPERATURE
}

\author{
J. KRYNICKI, H. RZEWUSKI, \\ Instytut Chemii i Techniki Jądrowej, Dorodna 16, Warszawa, Poland \\ R. Groetzschel \\ Zentralinstitut für Kernforschung Rossendorf/Dresden, Germany
}

and A. Claverie

CEMES-LOE CNRS, 31055 Toulouse, France

(Received August 8, 1990)

\begin{abstract}
Amorphization of $\mathrm{GaAs}$ implanted with $\mathrm{Cd}$ in the dose range of $2 \times 10^{13}-$ $1.2 \times 10^{14}$ ions $/ \mathrm{cm}^{2}$ and the energy range of 20 to $180 \mathrm{keV}$ at room temperature has been investigated. The degree and the depth distributions of postimplanted damage were measured by using RBS technique. The critical dose for each Cd-ion energy was determined. The amorphization models have been discussed. The results obtained are in agreement with theoretical predictions supporting heterogeneous amorphization of Cd-implanted GaAs at room temperature.
\end{abstract}

PACS numbers: $61.80 . \mathrm{Jh}, 61.70 . \mathrm{Tm}$

\section{Introduction}

The mechanisms of amorphization in ion implanted III-V compound semiconductors and the models for crystalline to amorphous transformation are still the aim of investigations and analyses.

The amorphization process much better understood in $\mathrm{Si}[1,2]$, in III-V compound is believed to occur in a different manner [3].

Two basic models are proposed for continuous amorphization under ion bombardment: 
(i) a model of homogeneous amorphization equivalent to a critical-energy-density model (CED), where the transformation to the amorphous state occurs at some critical values of defect concentration created by elastic nuclear collisions, [4];

(ii) a heterogeneous model which assumes that accumulation of overlapping amorphized clusters produces full amorphization $[5,6]$.

It is believed that the above mentioned models operate for light and heavy ions, respectively.

In this paper, we report the results on the formation of an amorphous layer in GaAs due to heavy Cd ion implantation at room temperature.

The calculations of an amorphous build-up versus dose have been performed to distinguish between these two models.

\section{Experimental}

Commercially available (Hoboken, Holland) GaAs $n$-type $\langle 100\rangle$ orientation wafers containing $2 \times 10^{17} \mathrm{~cm}^{-3}$ Te atoms were used. All samples have been implanted with doses in the range from $1 \times 10^{13}$ to $1.2 \times 10^{14} \mathrm{ions} / \mathrm{cm}^{2}$ and in the energy range from 20 to $180 \mathrm{keV}$ at room temperature. They were slightly misoriented in order to minimize channeling. For comparison the $\mathrm{Cd}$ ion implantations at $120 \mathrm{keV}$ and doses from $3 \times 10^{13}$ to $1.2 \times 10^{14}$ ions $/ \mathrm{cm}^{2}$ have been performed. To a void heating of the samples a flux lower than $1 \mu \mathrm{A} / \mathrm{cm}^{2}$ was used. The temperature of the samples was monitored by a copper/constantan thermocouple and was kept below $40^{\circ} \mathrm{C}$.

Disorder distributions were measured using Rutherford backscattering technique with $1.7 \mathrm{MeV}{ }^{4} \mathrm{He}^{+}$ions. The critical dose for amorphization and the width of amorphized layer for each Cd ion energy have been determined.

\section{Results and Discussion}

Damage depth profiles of the implanted layers have been calculated from the experimentally obtained RBS spectra.

Figure 1 shows a set of curves representing the damage distributions for $\mathrm{Cd}$ ion energies from $20 \mathrm{keV}$ to $180 \mathrm{keV}$ after $\mathrm{Cd}$ implantation with a dose of $9 \times 10^{2} \mathrm{~cm}^{-2}$.

Additional measurements i.e. damage profiles versus dose were performed for 80,120 and $180 \mathrm{keV}$ of Cd-ions but not included in the paper. To verify the validity of the amorphization models two independent calculations based on the experimental data have been performed. Figure 2 shows the damage created versus dose of $20 \mathrm{keV}$ and $40 \mathrm{keV}$ Cd-ion implantation superimposed on the theoretical curves calculated for the first $(m=1)$ and the second $(m=2)$ order of amorphization in the overlap-damage model considered by Gibbons [5]. The experimental points are situated much closer to the $m=1$ theoretical curve than the one of $m=2$ which 


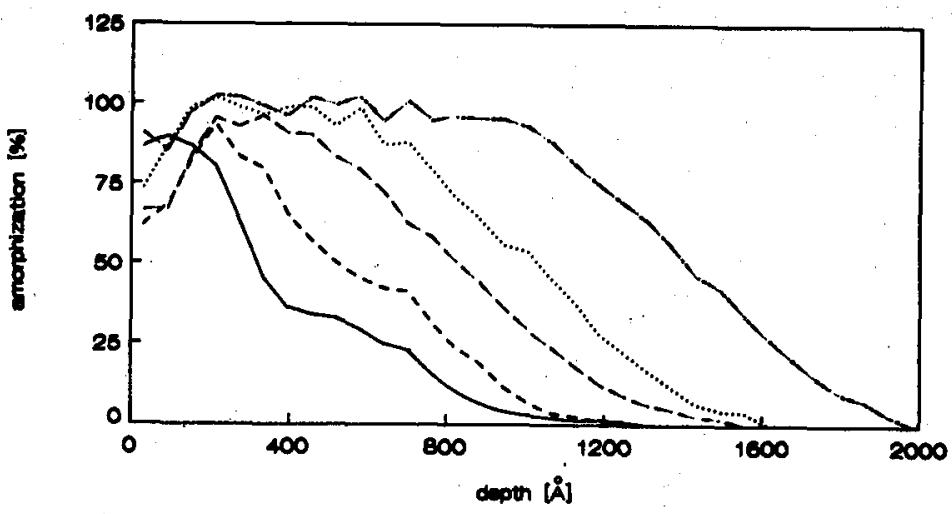

Fig. 1. Damage distributions in GaAs implanted with dose $9 \times 10^{13} \mathrm{~cm}^{-2}$ with energy $20 \mathrm{keV}(-), 40 \mathrm{keV}(--), 80 \mathrm{keV}(--), 120 \mathrm{keV}(\cdots)$ and $180 \mathrm{keV}(-\cdot-)$.

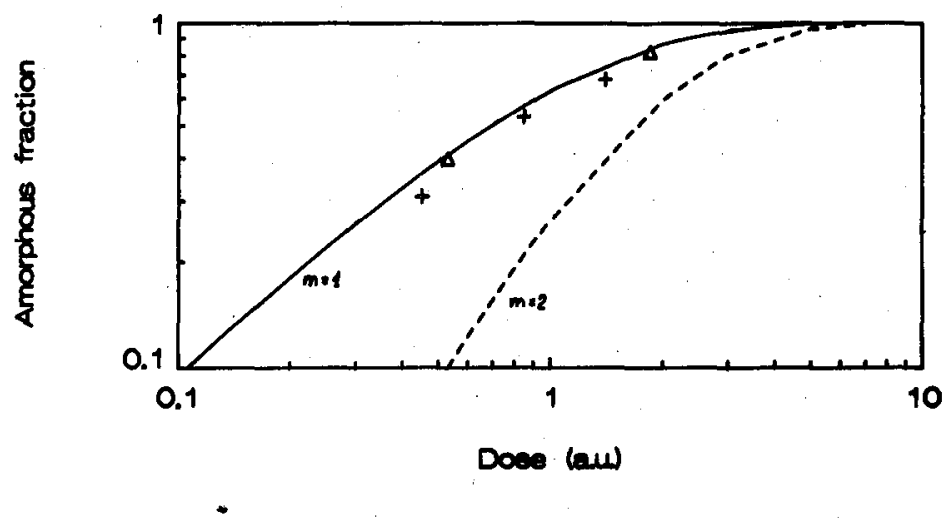

Fig. 2. Fit to overlap model [5] for $20 \mathrm{keV}(+)$ and $40 \mathrm{keV}(\Delta) \mathrm{Cd}$ ion implantation; $\mathrm{m}=1(-), \mathrm{m}=2(---)$. 
corresponds to direct amorphization by the first ion which supports the validity of this model.

TABLE I

\begin{tabular}{r|r|l}
\hline \hline $\begin{array}{r}\text { Energy } \\
\text { keV }\end{array}$ & \multicolumn{3}{|c}{$\begin{array}{l}\text { Critical dose } \\
\times 10^{13} \mathrm{~cm}^{-2}\end{array}$} \\
\hline 20 & 10 & $(*)$ \\
40 & 8 & $(*)$ \\
80 & 5.5 & $(* *)$ \\
120 & 4 & $(* *)$ \\
180 & 1.8 & $(* *)$
\end{tabular}

(*) Extrapolated dose for

$95 \%$ of amorphization at $R_{P}$

(**) A dose for $95 \%$

of amorphization at $R_{P}$
TABLE II

\begin{tabular}{r|c}
\hline $\begin{array}{r}\text { Energy } \\
\mathrm{keV}\end{array}$ & $\begin{array}{c}\text { Critical energy density } \\
\times 10^{23} \mathrm{eVm}^{-2}\end{array}$ \\
\hline 20 & 1.75 \\
40 & 1.80 \\
80 & 1.47 \\
120 & 1.15 \\
180 & 0.55
\end{tabular}

To verify the next CED model, critical energy density values have been calculated using simulation method of Vieu et al. [7] (see Table I). For homogeneous amorphization the critical energy density versus implantation energies used should be constant. It is not the case, the successive values differ by a factor 3 in the range of implantation from 20 to $180 \mathrm{keV}$ and therefore, the CED model cannot be used.

It is worth to note that for each Cd-ion energy the distribution of postimplantation defects is non symmetric with respect to the equivalent $R_{p}$ for defects (see Fig. 1). The density of permanent defects grows much faster in the bulk than the density close to the surface. For all implantation energies the observed damage distributions show the presence of tails, indicating a relatively high concentration of defects occuring deeper than the implanted ions. Two mechanisms can be responsible for this effect - fast diffusion of defects being pinned in the bulk and the recoil implantation process which transfers energy of knocked out matrix atom into the bulk.

The critical doses presented in Table II show strong dependence on the implantation energy used. Defects created very closely to the surface crystal have a very high probability to diffuse to the surface and annihilate there.

\section{Conclusion}

From the detailed investigations of the measured degree of amorphization caused by the Cd implantation into GaAs at room temperature, it is concluded that the results obtained support the theoretical predictions of a heterogenous model of amorphization.

The observed dependence of a critical dose versus Cd-ion energy is ascribed to the annihilation of defects created close to the surface of a crystal for lower energy of implantation which requires a higher dose for amorphization for these energies. 


\section{References}

[1] J.R. Dennis, E.B. Hale, Radiat. Eff. 30, 219 (1976).

[2] S. Prussin, D.I. Margolose, R.N. Tauber, Appl. Phys. 57, 180 (1985).

[3] D.K. Sadana, Nucl. Instrum. Methods Phys. Res. B 7/8, 375 (1985).

[4] H.J. Stein, F.L. Vook, D.K. Brice, A. Borders, T. Picraux, in Proc. 1st Internat. Conf. Ion Implantation, ed. L.T. Chadderton and F.H. Eisen, Gordon and Breach, London 1971, p. 17.

[5] J.F. Gibbons, Proc. IEEE 60, 1062 (1972).

[6] F.F. Morehead, B.L. Crowder, Radiat. Eff. 6, 27 (1970).

[7] C. Vieu, A. Claverie, J. Faure, J. Beavillain, Nucl. Instrum. Methods Phys. Res. B 28, 229 (1987). 